\title{
Influence of Laser Heating on the Properties of Coated Cutting Inserts
}

\author{
Maciej Jan Kupczyk ${ }^{1}$ \\ 1 Poznan University of Technology, Faculty of Mechanical Engineering, Institute of Mechanical Technology, \\ ul. Piotrowo 3, 60-965 Poznan, Poland \\ * Corresponding author's e-mail: maciej.kupczyk@put.poznan.pl
}

\begin{abstract}
The article presents the results of the influence of laser heating on the properties of replaceable cutting inserts with various anti-wear coatings. Based on the existing own and external publications, it was found that in order to improve the cutting properties (durability in the cutting process of steel), it is extremely important to increase the adhesion strength of hard coatings to the cutting inserts. For this purpose, laser heating with different values of the laser beam power density was used. First, the measurements of the adhesion, and then the wear and durability of the cutting blades in the process of longitudinal turning of the commonly used nitriding steel were carried out. In order to confirm the adhesion measurements carried out on the basis of the vibration signal evaluation, observations were additionally made using a scanning microscope and using 2D and 3D images on a profilometer. As a result of the research, it was found, among other things, a significant correlation between the values of adhesion of coatings to cemented carbide substrates and the durability of the blades in the steel turning process. A significant effect of laser heating on the above-mentioned properties of replaceable cutting inserts was observed. The most favorable value of the applied power density was determined, for which the blades have the best cutting properties. The research indicate that significant increase in adhesion and tool life can be achieved for the laser beam power density of up to $8280 \mathrm{~W} / \mathrm{cm}^{2}$. In the most favorable case, an increase in tool life of about $48 \%$ was obtained for the indexable cutting insert with a TiCN coating when turning 41CrAlMo7-10 steel.
\end{abstract}

Keywords: anti-wear coatings, laser heating, turning, tool life.

\section{INTRODUCTION}

Clearly selecting a specific compound for its suitability as a protective coating for the blades of metalworking cutting tools is a complex task. This is due to the different properties of the compounds used for coatings which selected depending on the needs $[1,2]$. As individual MeX compounds (Me - metal, X - non-metal) are predisposed to work in various machining conditions, it is necessary to define the hierarchy of importance of individual characteristics of these compounds in terms of meeting the basic operational requirements. Due to the conditions in which the cutting tool blades work, the basic requirement for protective coatings, regardless of the type of steel processed, is the highest possible resistance to brittle fracture under the pressure occurring in the cutting zone and similar values of the coefficient of thermal expansions of the MeX compound and the substrate material. This condition also results from own research $[3,4]$, on the basis of which it was found that the dominant symptom of wear of thin, hard coatings deposited on the cutting blades is their cracking and detachment of the "micro-flakes" of coatings as results of hook up of the micro-gaps by chip and the workpiece, and only then abrasive wear. In the case of machining lowcarbon steels, additional adhesive wear occurs in the form of tacking (built-up edge). However, abrasive wear is a significant factor when machining high carbon steels and cast irons. Therefore, the coatings used in these conditions should be particularly resistant to this form of wear. For the vast majority of MeX compounds (e.g. nitrides, borides, silicas of transition metals) there is a linear relationship between hardness and wear resistance [3, 4]. 
It turns out, however, that the application of an appropriate anti-wear coating to the cutting insert is not a sufficient condition for it to be characterized by increased durability in the cutting process compared to uncoated inserts. Studies have shown that the use of an anti-wear coating with high temperature resistance, high hardness, dense structure and appropriate chemical composition on the cutting insert is not enough to fulfill the protective function of the cutting tool. It turns out that the basic parameter is very good adhesion to the substrate [5-8].

As mentioned earlier, this is due to the fact that in the cutting zone there are very high unit pressures on the rake surface and the side surface of the cutting insert. For the above reasons, in the case of insufficient adhesion of the coating to the substrate, it is almost immediately removed from the area of chip interaction and the workpiece $[3,4,9]$.

The value of the adhesion force between solids (in the discussed case between the coating and the substrate) depends not only on the type of coating and substrate materials, but also to a large extent on the form of the transition layer [1-3, 9]. Thus, when analyzing the adhesion, attention should be paid to the overall nature of the transition layer.

The following transition layers are most often distinguished $[1,4,9,10]$ : mechanical, monolayer on a monolayer, chemical, diffusion, pseudodiffusion, remelting, epitaxial, complex.

The mechanical transition layer forms on rough and porous substrates. The coating material, filling the pores or other morphologically advantageous places of the substrate, forms the mechanical anchorage. In this type of transition layer, chemical reactions take place sporadically, and the bond strength depends mainly on the mechanical anchoring of the coating to the unevenness of the substrate surface. The adhesion in this case depends on the mechanical properties (especially the shear strength and plasticity) of the adjoining materials. The surfaces of the substrates are sometimes deliberately roughened to increase the effect of the so-called mechanical anchorage [3]. However, this is disadvantageous due to the shading phenomenon, resulting in the formation of porous (not very dense) coatings with a columnar structure or with conical grains characteristic for zone I according to the Movchan-Demchishin and Thornton models $[4,11,12]$.

A chemical layer is formed when the atoms of the coating and substrate materials react with each other to form chemical compounds (eg oxides, nitrides) or intermetallic compounds $[2$, $3,10,13]$. This type of layer is characterized by a constant chemical composition and a thickness of a few or even many fixed networks [10]. The compounds formed in such a transition zone are usually brittle materials. When creating a chemical interface, pollutants are often segregated at the interface and stresses appear due to the mismatch of the crystal lattices [13, 14]. Sometimes pores develop in the union transition layer.

Interface in the form of monolayer on a monolayer (abrupt change), is characterized by a sudden transition from the coating material to the substrate material. This layer has a thickness

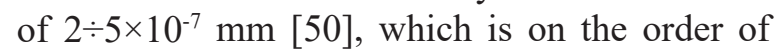
the interatomic distance. This type of transition layers are formed when chemical reactions occur sporadically between the coating and substrate materials, and also when diffusion does not occur [10] due to the lack of mutual solubility of materials or the presence of impurities on the surface of the substrate, preventing chemical reactions or diffusion of both materials. The formation this transition layer is also favored by the compact and smooth surface of the substrate. In this type of transition layer, the occurrence of stresses and defects is limited to a very narrow area $[4,10]$.

The diffusion transition layer, unlike the monolayer on monolayer, is formed mainly on the substrate with high temperature during the application of the coating, when there is a significant mutual solubility of the coating and substrate materials $[4,6]$. This area is characterized by a gradual change in the chemical composition, stresses and constant lattice. The diffusion layer has the advantageous characteristics of being an intermediate layer between very different materials, as it causes, inter alia, reduction of mechanical stresses resulting from the disproportions between the values of the thermal expansion coefficient of the coating material and the substrate. The structure of the diffusion transition layer is hindered by the presence of oxides or other impurities on the substrate. An additional advantage of diffusion processes is that if there are areas of low nucleation density on the substrate surface, the gaps in the transition layer may be filled with the coating material [4]. The formation of such an intermediate layer, however, requires a sufficiently high temperature, higher than that associated with the typical PVD processes.

The pseudo-diffusion transition layer can be created by the implantation of high-energy 
particles or by sputtering and ionic plating of the substrate material with simultaneous condensation of the coating material $[2-4,10]$, as well as by detonation covering. This type of transition layer has the same advantageous characteristics as the diffusion transition layer, but in contrast can be formed from materials that do not diffuse each other (are mutually insoluble). Pseudo-diffusion transition layers, like diffusion layers, can be classified as gradual interfaces. Increasing the "solubility" in the transition layer can be achieved by creating a higher concentration of defects and a stress gradient by ion bombardment of the substrate surface before the coating process [1-4].

The remelting transition layer is formed as a result of the mixing of the coating materials and the surface area of the substrate in the hard-facing or alloying. Hardfacing consists in melting with an electron beam the coating material applied to the substrate in the form of, for example, wire or powder. In this process, the substrate may also slightly melt. Alloying is a process that occurs in two types - as remelting or fusing. Remelting consists in melting the coating material (most often in the form of films or tapes deposited on the substrate) with its top layer. As a result of remelting, a transition layer is obtained, which is an alloy of both materials $[1,2]$, similarly to melting.

An epitaxial transition layer is a layer in which the crystal structure of the coating is an extension of the crystal structure of the substrate. Its formation is possible when the network parameters of the coating material will not differ from the network parameters of the substrate by more than $10-25 \%$ $[1,2]$. The epitaxial transition layer is mainly obtained from the production of coatings by electrolytic or PVD methods. Of course, complex transition layers can arise as well, being a combination of several interfaces described above [15-17].

The above analysis shows that one of the methods of increasing the adhesion of PVD coatings on cemented carbides may be to intensively heat the coating in order to create conditions for the diffusion process between the coating material and the substrate. As shown above, based on the analysis of the literature, this type of transition layer (diffusion or adhesive-diffusion) should have better properties than the solely adhesive interfacial layer.

In the present study, it was assumed that it would be beneficial to study the effect of laser heating on increasing the adhesion of the antiwear coating to the cutting inserts. The results of the research presented in this article are a continuation of the author's work on increasing the durability of cutting tools with anti-wear coatings. The comparative studies presented in this paper contain data on the adhesion of coatings to cemented carbide substrates and the results of the durability of cutting inserts before and after laser heating.

\section{CONDITIONS OF INVESTIGATIONS}

\section{Replaceable cutting inserts}

Three types of coatings were selected for the tests, namely $\mathrm{TiCN}, \mathrm{Al}_{2} \mathrm{O}_{3}+\mathrm{TiC}$ and $\mathrm{TiC}$ obtained by the PVD (arc-plasma) method. These coatings were deposited on a cemented carbide substrate of the S10S grade (P10-P20). S10S sintered carbide

a)

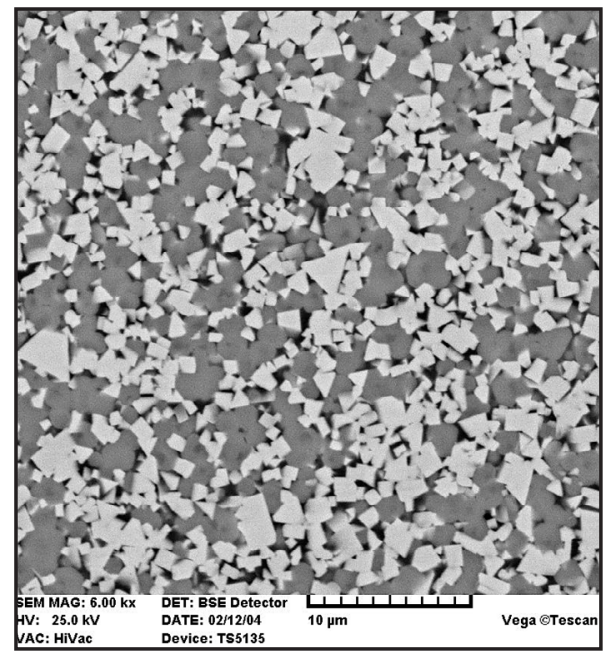

b)

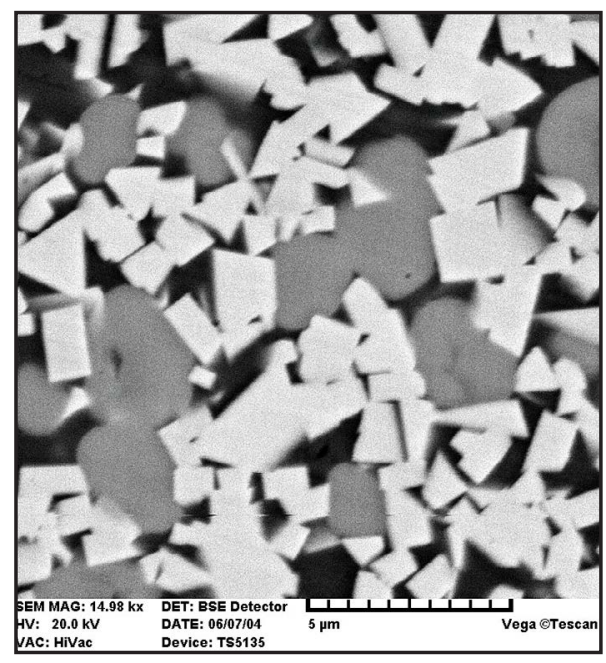

Fig. 1. Metallographic microstructure of the S10S sintered carbides; magnification of: a) 6000x, b) 15000x (where: white colour - WC; grey colour - (Ta, Nb, W) $\mathrm{C}$; black colour - binding phase $\mathrm{Co}$; designation of phases on the basis of $[4,19]$ ) 
is intended for fine and medium-fine machining of steel, cast steel and low-alloy cast steel at high cutting speeds and low feeds. S10S tungsten carbides are characterized by a high hardness of 1600 HV30, and thus good abrasion resistance, and retain these properties up to a temperature of 700 $1000{ }^{\circ} \mathrm{C}$ [18]. The uncoated cutting inserts are manufactured by Baildonit. The most important properties of these carbides, apart from the hardness mentioned earlier, include chemical composition: $\mathrm{WC}-56 \%$, $\mathrm{Co}-9 \%, \mathrm{TiC}+\mathrm{TaC}+\mathrm{NbC}$ $-35 \%$, flexural strength: $1600 \mathrm{MPa}\left(\mathrm{N} / \mathrm{mm}^{2}\right)$, average grain diameter: $3 \mu \mathrm{m}$, density: $10.1 \mathrm{~g} / \mathrm{cm}^{3}$ [4]. Figure 1 shows the metallographic specimens of the S10S sintered carbide.

\section{Laser heating conditions}

Cutting inserts made of sintered carbides, after the deposition of hard coatings on them, were subjected to laser heating. For laser heating, a $\mathrm{CO}_{2}$ TLF 2600T laser was used, installed in the Division of Machining of the Poznan University of Technology. The samples were not covered with black gouache because, as shown in previous studies [4], it is difficult to remove after laser heating for the purpose of subsequent, correct microanalysis and morphology estimation of the coating surface.

The following power density values were used during laser heating: 4140, 6210, 8280, 10350 and $12420 \mathrm{~W} / \mathrm{cm}^{2}$. The diameter of the laser beam was $3.75 \mathrm{~mm}$ (the beam was focused at a distance of $37.5 \mathrm{~mm}$ above the heated surface) and the scanning speed was $1.29 \mathrm{~m} / \mathrm{min}$. The above power density values were obtained using 20,30, 40, 50 and 60 percent of the maximum laser power, respectively. The laser was equipped with a Laser Carl Zeiss LBK-FP2 laser head (focal length $86.83 \mathrm{~mm}$ ).

\section{Adhesion measurement conditions}

Measurements of the adhesion of coatings to the substrates before and after laser heating were carried out on the critical load measuring station
UMT 2/3 Test System produced by Bruker Nano, installed in the Anti-Wear Coatings Laboratory at the Institute of Mechanical Technology Poznan University of Technology.

In accordance with previous studies, the following parameters of the scratch test were adopted as recommended [3]:

- $d L / d t=150 \mathrm{~N} / \mathrm{min}$ (loading rate),

- $d x / d t=7.5 \mathrm{~mm} / \mathrm{min}$ (scratching speed),

- $R=0.20 \mathrm{~mm}$ (radius of diamond stylus),

- ratio $d L / d x=20 \mathrm{~N} \mathrm{~mm}^{-1}$.

When scratching the coating, the load was gradually increased from 0 to $100 \mathrm{~N}$. The obtained adhesion test results using the scratch test were verified using 2D and 3D images obtained on the Waveline T8000 Hommelwerke profilometer. The verification of adhesion measurements was also performed using a Tescan Vega 5135 scanning microscope.

\section{Cutting conditions}

To check the functional properties of the cutting inserts after laser heating, tests were carried out on the wear and durability of the blades during longitudinal turning of 41CrAlMo7-10 (38HMJ) nitriding steel on a TK66 lathe.

The following machining parameters were used during the wear and durability tests of the cutting inserts:

- cutting speed $v_{c}=120 \mathrm{~m} / \mathrm{min}$,

- feed speed $v_{f}=0.076 \mathrm{~m} / \mathrm{min}($ feed $f=0.2$ $\mathrm{mm} / \mathrm{rev}$ ),

- depth of cut $a_{p}=1 \mathrm{~mm}$,

- workpiece: $41 \mathrm{CrAlMo} 7-10$ steel with a hardness of $230 \mathrm{HB}$.

In the tests, rectangular cutting inserts with dimensions $12.7 \times 12.7 \times 4.76 \mathrm{~mm}$ were used, which after mounting in the toolholder of the CSRNR 252509-ID type the following geometry have obtained: $\varepsilon_{r}=90^{\circ}, \alpha_{0}=6^{\circ}, \gamma_{0}=-6^{\circ}, K_{r}=75^{\circ}, \lambda_{s}=-6^{\circ}$. The chemical composition of workpiece material (41CrAlMo7-10) is presented in Table 1.

Table 1. Chemical analysis of 41CrAlMo7-10 steel in \% according to PN-EN 10085:2002

\begin{tabular}{|c|c|c|c|c|c|}
\hline $\mathrm{C}$ & $\mathrm{Mn}$ & $\mathrm{Si}$ & $\mathrm{P}$ & $\mathrm{S}$ & $\mathrm{Cr}$ \\
\hline $0.35-0.42$ & $0.3-0.6$ & $0.17-0.37$ & $\max 0.025$ & $\max 0.025$ & $1.35-1.65$ \\
\hline $\mathrm{Ni}$ & $\mathrm{Mo}$ & $\mathrm{W}$ & $\mathrm{V}$ & $\mathrm{Co}$ & $\mathrm{Al}$ \\
\hline $\max 0.25$ & $0.15-0.25$ & $\max 0.2$ & $\max 0.05$ & - & $0.7-1.1$ \\
\hline
\end{tabular}


The basic mechanical properties of 41CrAlMo7-10 steel include according to PN-EN 10085:2002 are following:

- tensile strength, $R_{m}>980 \mathrm{MPa}$,

- the yield point, $R_{p 0.2}>830 \mathrm{MPa}$,

- elongation, $A>14 \%$,

- percent reduction of area of the specimen, $Z>50 \%$.

41CrAlMo7-10 (38HMJ) chromium-molybdenum steel is steel for nitriding. It is used for structural parts with high surface hardness $>900$ $\mathrm{HV}$ after nitriding and core strength $\sim 1000 \mathrm{MPa}$. Products made of this steel, after nitriding, obtain high abrasion resistance due to the content of aluminum and chromium, as well as molybdenum, titanium and vanadium, which during nitriding form hard nitrides AlN, CrN, MoN, TiN, VN. The hardness of the surface layer after nitriding does not decrease after heating to $500{ }^{\circ} \mathrm{C}$. Hence wide application of this steel.

\section{RESULTS}

\section{Results of adhesion}

Figure 2 shows an exemplary image of a cutting insert scratch obtained on the profilometer with a gradually increasing load on the diamond stylus tip during the scratch test. The area of the scanned surface was $2.7 \mathrm{~mm}=14 \mathrm{~mm}^{2}$.

In Table 2 the values of adhesion force $\left(L_{c}\right)$ for selected types of wear-resistant coatings deposited on sintered carbides interchangeable cutting inserts are shown.

As stated in the test conditions section, 2D and 3D images were recorded using a Waveline T8000 Hommelwerke profilometer. Pictures were obtained as positives and negatives. Positive images

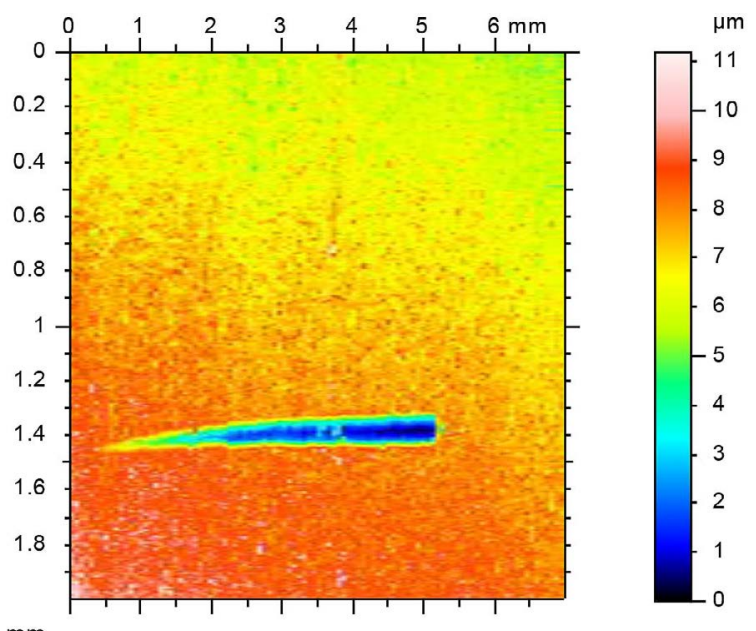

Fig. 2. An example of a scratch image of the cutting insert obtained on a profilometer with a gradually increasing load on the diamond stylus during the scratch test

were used to compare the surface morphology of the replaceable inserts first before and then after the heating process, while negative images were useful for assessing the critical load $L_{c}$.

Below are presented pictures of the scratch of the TiCN hard layer applied on the S10S (P10P20) substrate. The images shown were taken with a progressively increasing load. Figure $3 \mathrm{a}$ shows the scratch image of the TiCN coating before heating, while Figure $3 \mathrm{~b}$ shows the scratch image after laser heating with $40 \%$ of $P_{\max }$.

In Figure 3 are shown 2D negative pictures for demonstration of $L_{c}$ increase of TiCN coating after heating. Figure 3 shows a sudden increase in the height of the protuberance associated with the detachment of the coating from the substrate. It should be emphasized that during using $60 \%$ of $P_{\max }$, the coating completely evaporated and the substrate partially melted.

On Figures 4 to 6 are presented the effect of laser heating on $L_{c}$ of $\mathrm{TiC}$, $\mathrm{TiCN}$ and $\mathrm{Al}_{2} \mathrm{O}_{3}+\mathrm{TiC}$

Table 2. Results of the measurements of critical load $L_{c}$ for the tested coatings deposited on the S10S carbide cutting insert before and after laser heating with different power

\begin{tabular}{|c|c|c|c|}
\hline \multirow{2}{*}{$\begin{array}{c}\text { Percent of maximum laser } \\
\text { power }\left(P_{\max }\right)\end{array}$} & TiC & TiCN & $\mathrm{Al}_{2} \mathrm{O}_{3}+\mathrm{TiC}$ \\
\cline { 2 - 4 } & \multicolumn{3}{|c|}{ Critical load values $L_{c}[\mathrm{~N}]$} \\
\hline 0 & $18.40 \pm 4.7$ & $37.31 \pm 3.7$ & $37.43 \pm 5.6$ \\
\hline 20 & $31.66 \pm 5.0$ & $42.65 \pm 4.9$ & $38.68 \pm 5.7$ \\
\hline 30 & $37.07 \pm 4.6$ & $55.60 \pm 7.6$ & $19.68 \pm 5.5$ \\
\hline 40 & $44.88 \pm 6.9$ & $71.41 \pm 7.0$ & $7.01 \pm 3.9$ \\
\hline 50 & $25.94 \pm 4.8$ & $29.92 \pm 5.8$ & \\
\hline 60 & \multicolumn{3}{|c|}{ Partial or total evaporation of coating and partial melting of substrate } \\
\hline
\end{tabular}


a) Alpha $=90^{\circ} \quad$ Beta $=89^{\circ}$

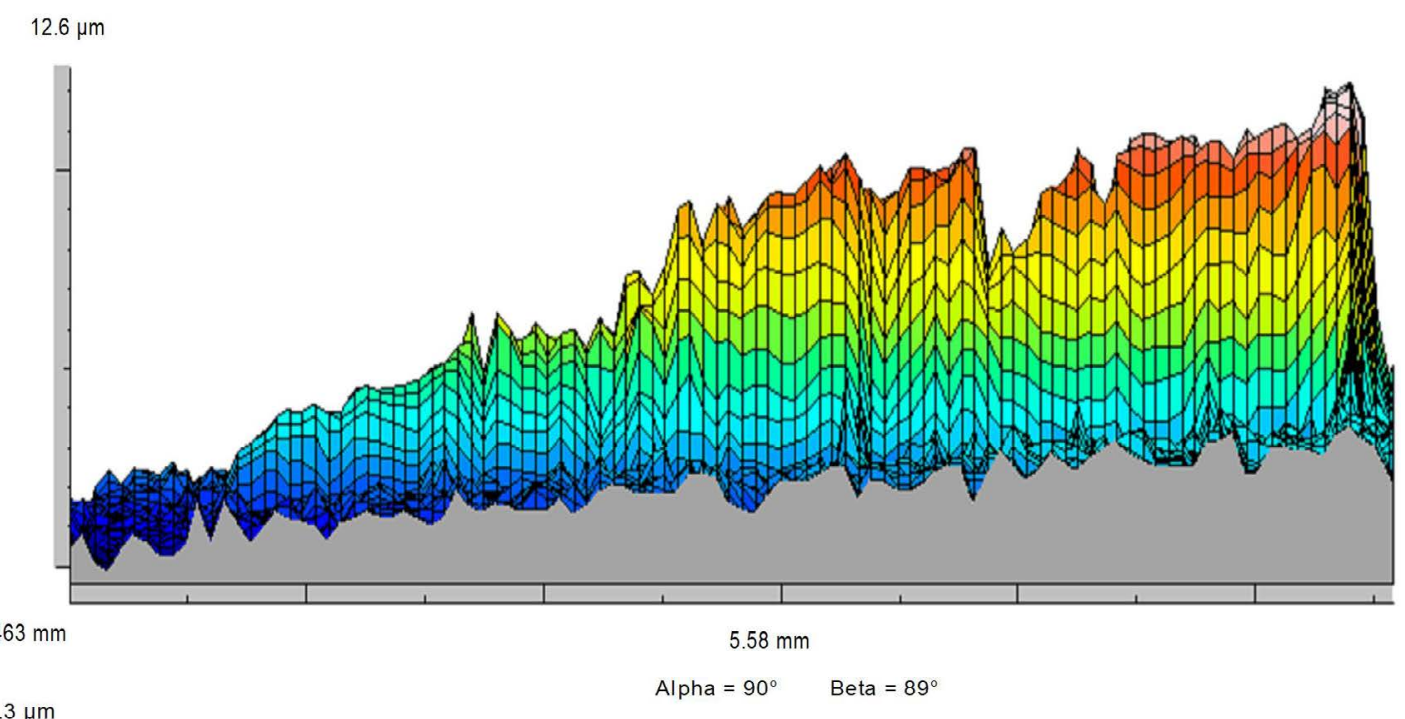

b)

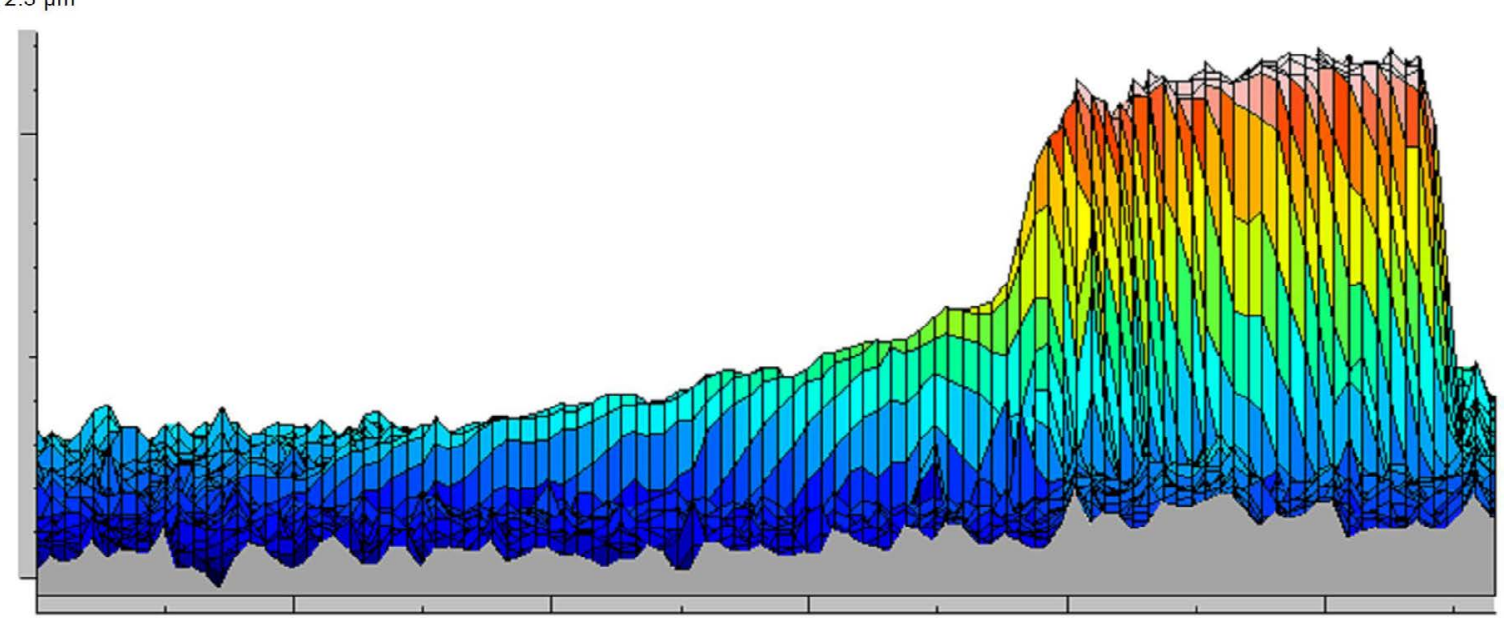

$.983 \mathrm{~mm}$

$5.66 \mathrm{~mm}$

Fig. 3. Sample negative scratch images of the TiCN coating deposited on S10S (P10-P2): a) before, b) after heating with $40 \%$ of $P_{\max }$ (where: axis of abscissae - scratch length, axis of ordinates - scratch depth)

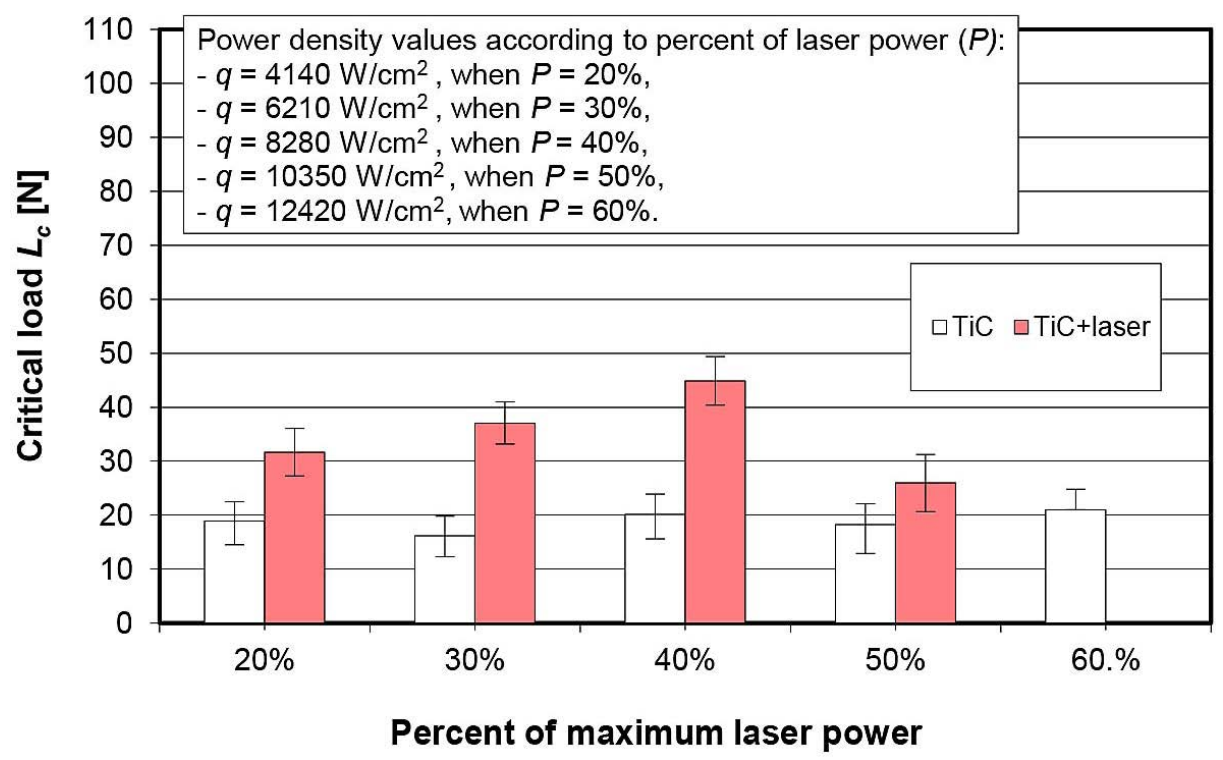

Fig. 4. A summary set of the results of TiC coating adhesion measurements to S10S (P10-P20) replaceable inserts 


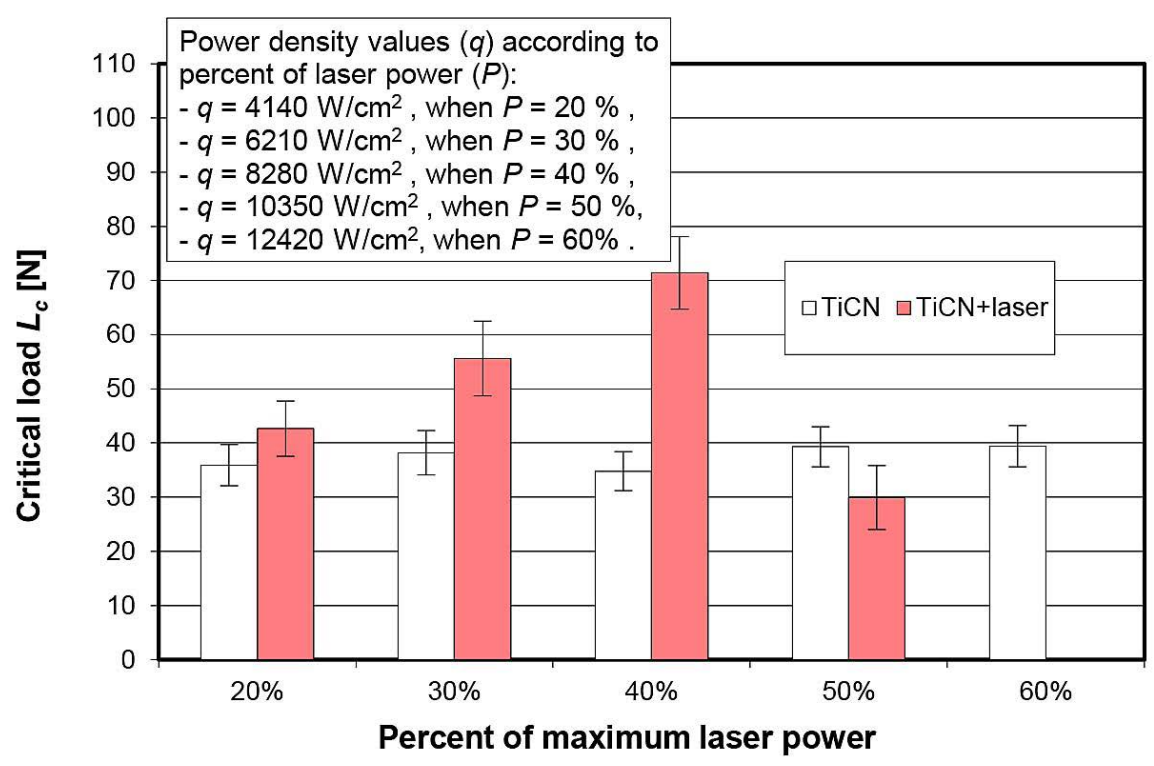

Fig. 5. A summary set of the results of TiCN coating adhesion measurements to S10S (P10-P20) replaceable inserts

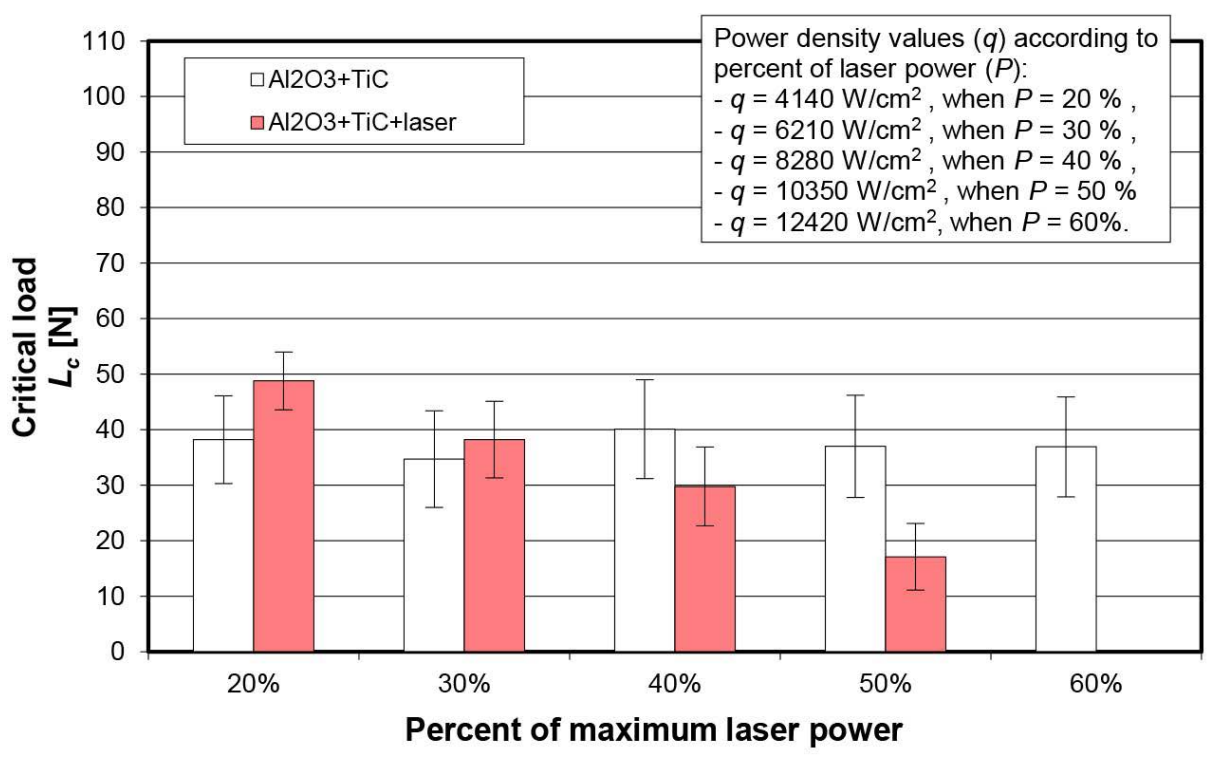

Fig. 6. A summary set of the results of $\mathrm{Al}_{2} \mathrm{O}_{3}+\mathrm{TiC}$ coating adhesion measurements to the S10S (P10-P20) replaceable inserts

coatings deposited on S10S replaceable inserts. On Figure 4 is shown that with the increase of laser heating from $20-40 \%$ of the $\mathrm{TiC}$ layer, the $L_{c}$ of the layer to the S10S sintered carbides improves. Higher power density values are not favorable. On Figure 5 is shown that for $\mathrm{TiCN}$ layer the average $L_{c}$ was considerable increased using $30 \%$ and even more for $40 \%$ of $P_{\text {max }}$. Unfortunately, bad tendency was noticed for the coating consisting of layers of aluminum oxide and titanium carbide as presented in Figure 6, since for all applied values of percent of $P_{\max }$ a considerable decrease of adhesion (critical load) was observed.
It follows that the presence of an aluminum oxide with low thermal shock resistance has a negative effect on the adhesion of the two-layer coat. In order to make a direct comparison of the adhesion of $\mathrm{TiC}, \mathrm{TiCN}$ and $\mathrm{Al}_{2} \mathrm{O}_{3}+\mathrm{TiC}$ coatings to the $\mathrm{S} 10 \mathrm{~S}$ cemented carbide substrate, Figure 7 summarizes the adhesion results for the most favorable variant, i.e. $40 \%$ of the maximum laser power.

Summarizing the observations regarding the adhesion studies, it should be noted that the difference between alumina $\left(\mathrm{Al}_{2} \mathrm{O}_{3}\right)$ and $\mathrm{TiCN}$ and $\mathrm{TiC}$ layers is related to the dominance of chemical bonds in above compounds $[4,5]$. TiCN) and 


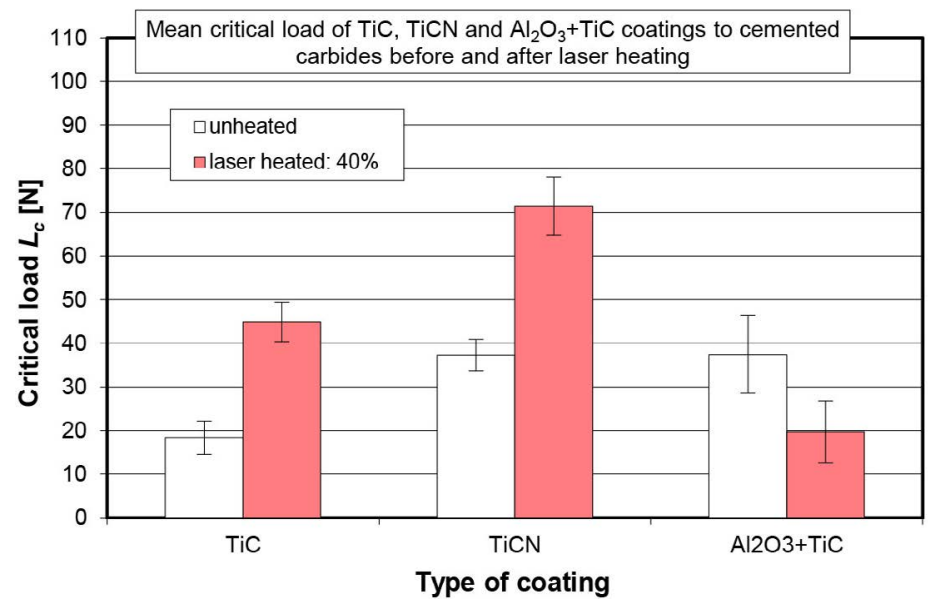

Fig. 7. Comparative set of heating effect (for $40 \%$ of $P_{\max }$ ) on critical load $\left(L_{c}\right)$ of $\mathrm{TiC}$, TiCN and $\mathrm{Al}_{2} \mathrm{O}_{3}+\mathrm{TiC}$ coatings to the $\mathrm{S} 10 \mathrm{~S}$ replaceable inserts

a)

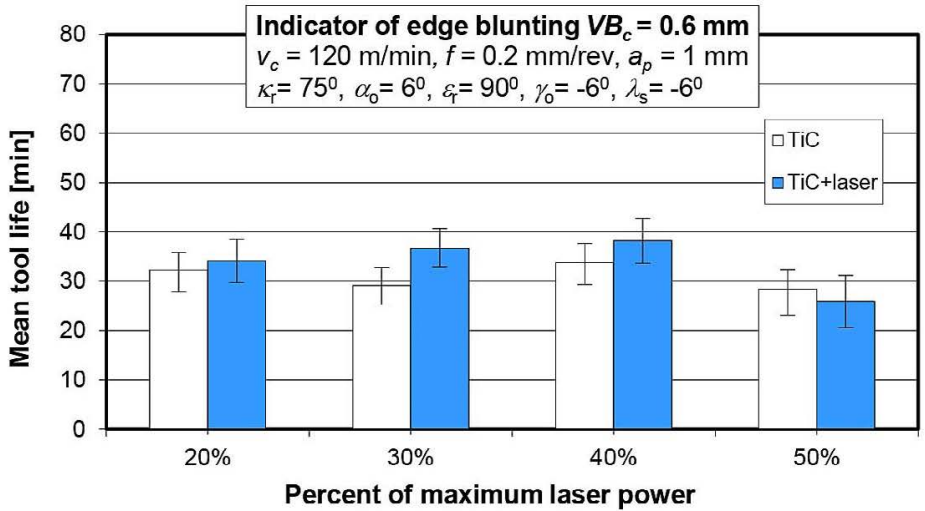

b)

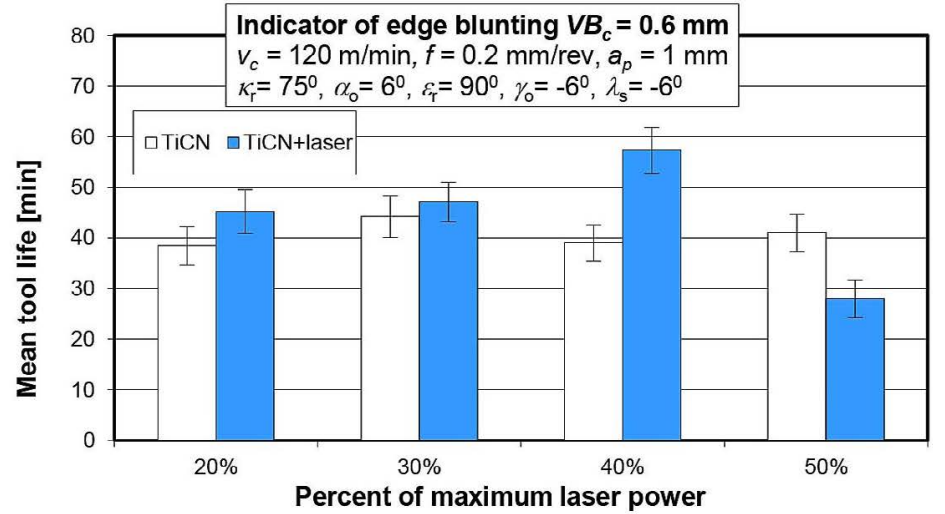

c)

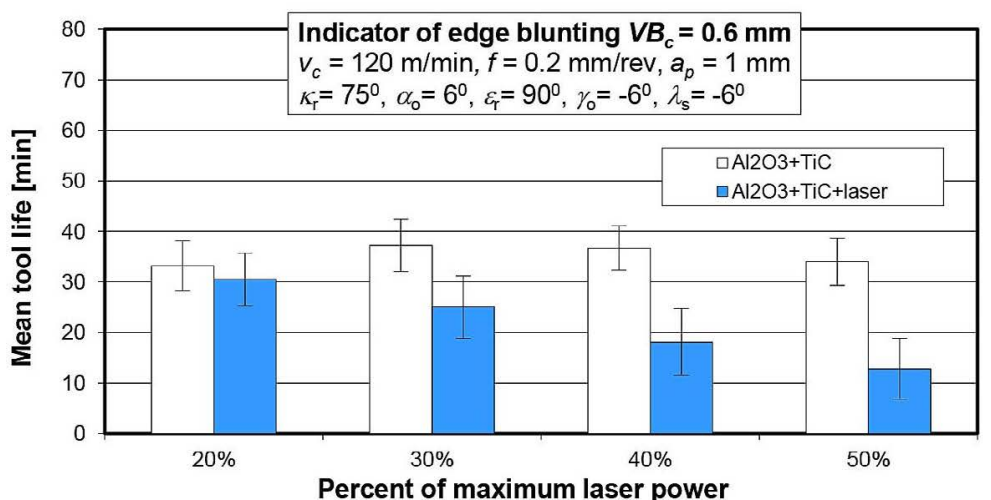

Fig. 8. Durability of cutting edges made of S10S steel coated with: a) TiC, b) TiCN and c) $\mathrm{Al}_{2} \mathrm{O}_{3}+\mathrm{TiC}$ during turning of 41CrAlMo7-10 (38HMJ) nitriding steel before and after laser heating (with different power density values) 
TiC have metallic-covalent bonds but aluminum oxide mostly have ionic bonds. Solids with a high proportion of ionic bonds, such as white i.e. oxide ceramics or SiC, are susceptible to thermic shock. Heating with a laser beam causes heat stroke. Hence, coatings that can be successfully subjected to laser heating, they should have adequate resistance to thermal shock.

\section{Results of tool life}

To check the functional properties of the cutting inserts after laser heating, tests were carried out on the wear and durability of the blades during longitudinal turning of 41CrAlMo7-10 nitriding steel in the form of shafts. Hardness of shafts made of the 41CrAlMo7-10 steel had $230 \mathrm{HB}$.

In order to determine the durability of the cutting blades, wear curves were determined. Tool life was determined for an indicator of the edge blunting $V B_{c}=0.6 \mathrm{~mm}$. Tool life was calculated for the edge blunting index $V B_{c}=0.6 \mathrm{~mm}$.

Figure 8 shows mean tool life of cutting edges for the S10S sintered carbides coated with $\mathrm{TiC}$, $\mathrm{TiCN}$ and $\mathrm{Al}_{2} \mathrm{O}_{3}+\mathrm{TiC}$ coatings during turning the 41CrAlMo7-10 (38HMJ) steel for different values of laser heating.

Figure 9 shows a comparison of the durability of tools made of S10S cemented carbides covered with $\mathrm{TiC}$, TiCN and $\mathrm{Al}_{2} \mathrm{O}_{3}+\mathrm{TiC}$ coatings during turning 41CrAlMo7-10 nitriding steel before and after laser heating with the most favourable laser power value.

In Figure 10 are presented SE images of cutting edges coated with $\mathrm{TiC}, \mathrm{TiCN}$ and $\mathrm{Al}_{2} \mathrm{O}_{3}+\mathrm{TiC}$ after heating by using $40 \%$ of $P_{\max }$. In Figure $10 \mathrm{c}$ are shown the typical cracks after laser heating in the coating containing the aluminum oxide layer. For example, Figure 11 shows a comparative set of SE images of a cutting blade with a TiC coating before and after the heating process.

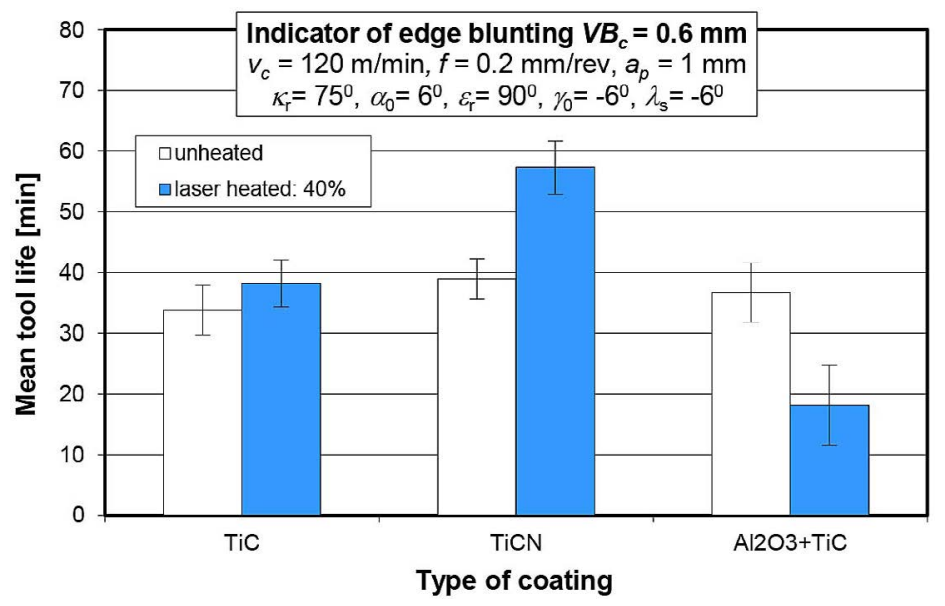

Fig. 9. Comparison of tool life of cutting edges made of S10S sintered carbides coated with: TiC, TiCN and $\mathrm{Al}_{2} \mathrm{O}_{3}+$ TiC during turning of $41 \mathrm{CrAlMo} 7-10$ steel before and after heating with $40 \%$ of $P_{\max }$

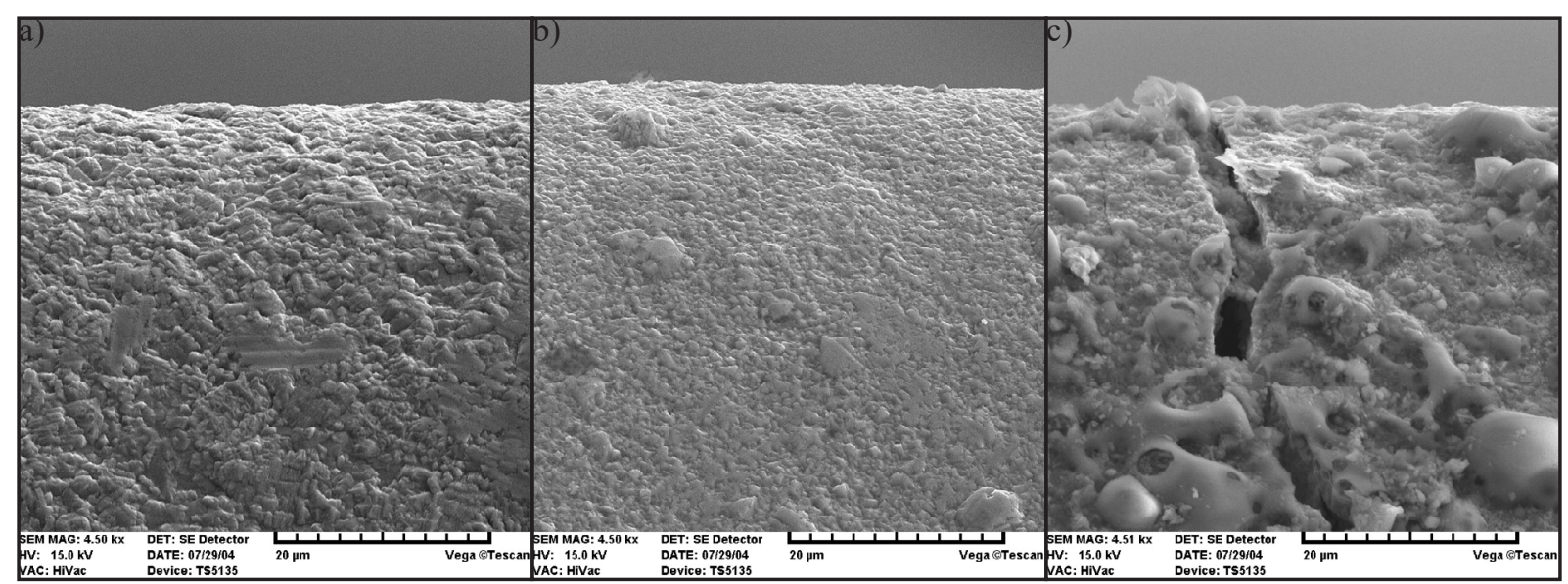

Fig. 10. SE images of cutting edges made of S10S sintered carbides coated with a) $\mathrm{TiC}, \mathrm{b}) \mathrm{TiCN}$ and c) $\mathrm{Al}_{2} \mathrm{O}_{3}+\mathrm{TiC}$ coating after heating by using $40 \%$ of $P_{\max }$ 
a)

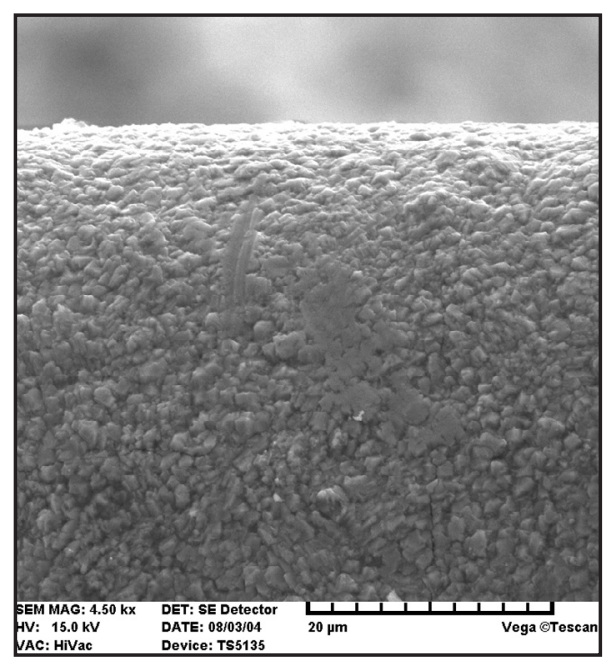

b)

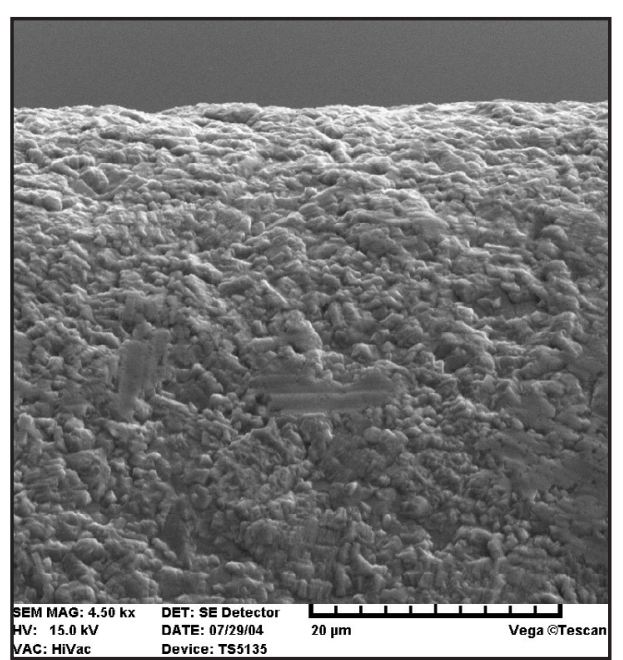

Fig. 11. SE images of cutting edges made of S10S sintered carbides coated with TiC: a) before

b) after heating by using $40 \%$ of $P_{\max }$

Referring to the above images, it should be stated that the average roughness of the $\mathrm{TiC}$ coating surface before and after heating using the power density of $8280 \mathrm{~W} / \mathrm{cm}^{2}$ was $\mathrm{Ra}=0.34 \mu \mathrm{m}$ and $\mathrm{Ra}=0.59 \mu \mathrm{m}$, respectively.

\section{CONCLUSIONS}

Based on the adhesion and durability researches and observations carried out on scanning electron microscope, the following conclusions can be drawn:

- investigations have shown a close correlation between the adhesion of hard coatings to cemented carbide blades and the tool life of replaceable cutting inserts when turning 41CrAlMo7-10 nitriding steel,

- as a result of laser heating, the critical load (adhesion) of PVD layers to the S10S substrate increases, but the result depends on the type of wear-resistant coating and the value of the power density used,

- observation and measurements indicate that essential increase in adhesion and tool life can be achieved for the laser beam power density of up to $8280 \mathrm{~W} / \mathrm{cm}^{2}$, but only for $\mathrm{TiC}$ and $\mathrm{TiCN}$ layers. Higher beam power $(50 \%$ of maximum laser power) reduces the adhesion of the coating to sintered carbides and durability during turning the 41CrAlMo7-10 nitriding steel,

- aluminum oxide coating should not be used for rapid laser heating due to its low resistance to thermic stroke (high risk of cracking) due to the dominance of ionic bonds in this chemical compound.

\section{Acknowledgements}

The author would like to thank for the financial support of Faculty of Mechanical Engineering PUT (project No 0614/SBAD/1529). The author also thanks Prof. P. Twardowski, Prof. D. Przestacki, Dr K. Jozwiak, MSc. J. Komolka and Mr. M. Kochanka for facilitating research with the use of a profile meter, a molecular laser stand, SEM and metal-turning lathe.

This work was financed from the funds of the Ministry of Education and Science by Agreement No. DNK/SP/513880/2021 of 22 December 2021, the project " $14^{\text {th }}$ School of Machining and the $43^{\text {rd }}$ Scientific School of Abrasive Machining", under the programme "Perfect Science".

\section{REFERENCES}

1. Burakowski T., Wierzchoń T. Surface engineering of metals - principles, equipment, technologies. CRC PRESS LLC - London-New York; 1998.

2. Burakowski T. Considerations on synergism in surface engineering. Publishing House of the Radom University of Technology; 2004.

3. Kupczyk M.J. Production and operation of cutting tools with anti-wear coatings. Publishing House of the Poznan University of Technology; 2009.

4. Kupczyk M.J. Surface engineering - cutting tools. Publishing House of the Poznan University of Technology; 2015.

5. Pancielejko M. Adhesion of PVD and CVD hard coatings as an essential parameter that determines the durability of coated tools. Archives of Material Science and Engineering. 2019; 96(1): 5-21.

6. Othman M.F., Bushroa A.R., Abdullah W.N.R. 
Evaluation techniques and improvements of adhesion strength for TiN coating in tool applications: a review. Journal of Adhesion Science and Technology. 2015; 29(7): 569-591.

7. Vopát T., Sahul M., Haršáni M., Vortel O., Zlámal T. The Tool life and coating-substrate adhesion of AlCrSiN-coated carbide cutting tools prepared by LARC with respect to the edge preparation and surface finishing. Micromachines. 2020; 11(2): 166-178.

8. Viana R.A. Machado R. Influence of adhesion between coating and substrate on the performance of coated HSS twist drills, Journal Braz. Soc. Mech. Sci. \& Eng. 2009; 31(4): 327-332.

9. Hinterman H.E. Adhesion, friction and wear of thin hard coatings. Wear. 1984; 100(1-3): 381-397.

10. Bunshah R.F., Blocher J., Bonifield T., Fish J., Ghate P.B., Jacobson B., Mattox D., Mc Guire G., Schwartz., Thornton J., Tucker R. Deposition technologies for films and coatings - developments and applications. Noyes Publications Park Ridge - New Jersey; 1995.

11. Thornton J.A. High rate thick film growth. Ann. Rev. Mater. Sci., 1977; 7: 239-260.
12. Movchan B.A., Demchishin A.V. Fiz. Metal. 1969; 28: 653-660

13. Pulker H.K., Perry A.J., Berger R. Adhesion. Surface Technology. 1981; 14: 25-30.

14. Bull S.J., Rickerby D.S. Multi-pass scratch testing as a model for abrasive wear. Thin Solid Films. 1989; 181(1-2): 545-553.

15. Farhan M.S. A review on adhesion strength of single and multilayer coatings and the evaluation method. Wasit Journal of Engineering Science. 2016; 4(1): 1-27.

16. Kanamori K., Kimoto Y., Toriumi S., Yonezu A. Evaluation of adhesion durability of Ni-P coating using repeated laser shock adhesion test. Surface and Coatings Technology. 2020; 396(25): 125953.

17. Ramamoorthy B., Yeldose B.C. An Investigation into the adhesion strength of diamond like carbon multilayer coating (DLC/TiN/Ti/Cu/Ni)B. Intelligent Information Management. 2009; 1: 179-194.

18. Mechanics Guide - Materials Science. Scientific and Technical Publishers (WNT); 1994.

19. Dobrzański L.A. Fundamentals of materials science and metal science. Scientific and Technical Publishers (WNT); 2002. 